\title{
SOME EPIDEMIOLOGICAL ASPECTS OF ACUTE RHEUMATISM
}

BY

\author{
DAVID HEWITT and ALICE STEWART \\ Institute of Social Medicine, Oxford
}

\section{INTRODUCTION}

In the autumn of 1947 , the notification of acute rheumatism became compulsory in the County Boroughs of Sheffield, Bristol, Grimsby, and Lincoln, and the Administrative County of Lincolnshire (Parts of Lindsey), thus providing opportunity for a fresh attack on some neglected problems of the disease. The Rheumatic Fever Committee of the Royal College of Physicians decided to exploit this opportunity by setting on foot a special study of the notified cases. The study dealt with the social background of the disease in general and was closely modelled on the Medical Research Council investigation of 1927 . The present paper is an abridged version of a report prepared for the Rheumatic Fever Committee of the Royal College of Physicians, but the responsibility for the form of analysis and for the conclusions drawn rests entirely with the authors.

In the regulation introducing notification (S.R. and O., No. 1828) acute rheumatism was defined as the following conditions occurring separately or together in a person under the age of 16 years:

(a) rheumatic pains or arthritis accompanied by a rise in temperature,

(b) rheumatic chorea,

(c) rheumatic carditis,

(d) valvular disease of the heart of rheumatic origin.

After formal notification, the diagnosis was either confirmed or rejected by one of three consultants who had previously agreed on common standards. The children were usually seen by the consultant within 3 months of notification, but in rural areas, where it was more difficult to make appointments, a final diagnosis might be delayed for more than a year. For each case a schedule describing home conditions, relatives, income, etc., was completed jointly by a health visitor and a sanitary inspector. In Sheffield, similar schedules were completed for a group of 471 non-rheumatic children between 5 and 14 who were attending day schools in the city during 1948 and whose birthdays fell on two selected days of the year. Since no control records could be prepared in Bristol or in Lindsey, epidemiological questions which do not necessitate the use of control material will be dealt with in Part I of the present report (all areas), and Part II will relate only to cases and controls in Sheffield.

\section{PART I}

A. Regional INCIDENCE.-The records of 593 notified cases, 566 of which had been confirmed by a consultant, were sent to the Institute of Social Medicine, Oxford, between August and December, 1951. These relate to children notified during the first $3 \frac{1}{4}$ years of the scheme (i.e. October, 1947, to December, 1950, inclusive). They include cases

(i) notified at the time of an initial attack,

(ii) notified at the time of a second, third, or fourth attack,

(iii) found to be suffering from heart lesions but with no definite history of acute rheumatism,

(iv) still awaiting final diagnosis (here assumed to be initial attacks).

A valid estimate of the current incidence of rheumatism should be based not on the total number of cases notified but on the number described as initial attacks. The estimated incidence can be further improved by the exclusion of cases belonging to 1947 , the incomplete year of notification, and of the small number of cases falling outside the age group 5 to 14 . This reduces the total number of cases to 381. Since these occurred in a population of 185,000 (Registrar General, 1949) they represent an annual notification rate of 69 per 100,000 .

If the notification areas, taken together, are representative of England and Wales, and if notification was complete, it follows that in the country as a whole, about 3,900 children between the ages of 5 and 14 develop acute rheumatism each year. This implies that there is, in this age group, one case of acute rheumatism to every twelve notified cases of scarlet fever. This ratio will be too low if the rheumatic notification (as compared with the scarlet fever notification) was incomplete, if screening was too strict, or if rheumatic fever was rarer in the notification areas than in the country as a whole. If, however, the rheumatic notifications were complete and the notification areas as a whole had an exceptionally heavy incidence of rheumatic fever, 
the ratio will be too high. Between the areas there appears to have been a range of variation fully as large as one would have expected to find in the country as a whole. This is illustrated in Table I.

TABLE I

ESTIMATED ANNUAL INCIDENCE OF ACUTE RHEUMATISM IN FOUR AREAS

\begin{tabular}{|c|c|c|c|c|}
\hline Area & $\begin{array}{c}\text { No. of New } \\
\text { Cases } \\
\text { Notified } \\
\text { aged 5-14 } \\
1948-50\end{array}$ & $\begin{array}{c}\text { Population } \\
\text { Aged } \\
5-14 \\
\text { in } \\
\text { Dec. } 1947\end{array}$ & $\begin{array}{c}\text { Approx. } \\
\text { Annual } \\
\text { Notification } \\
\text { Rate per } \\
100,000\end{array}$ & $\begin{array}{l}\text { Notification } \\
\text { Rate as a } \\
\text { Percentage } \\
\text { of that for } \\
\text { All Areas }\end{array}$ \\
\hline \multirow{3}{*}{$\begin{array}{l}\text { Sheffield C.B. } \\
\text { Bristol C.B. } \\
\text { Grimsby and } \\
\text { Lincoln } \\
\text { Remainder of } \\
\text { Lindsey A.C. }\end{array}$} & $\begin{array}{l}184 \\
105\end{array}$ & $\begin{array}{l}68,293 \\
54,362\end{array}$ & $\begin{array}{l}90 \\
64\end{array}$ & $\begin{array}{r}130 \\
93\end{array}$ \\
\hline & 41 & 21,918 & 62 & 90 \\
\hline & $51^{*}$ & 40,808 & 42 & 61 \\
\hline All Areas & $381^{*}$ & 185,381 & 69 & 100 \\
\hline
\end{tabular}

* A small number of cases in this total may eventually be classified as non-rheumatic, or as secondary attacks.

According to the estimates in this table the notification rate in the industrial city of Sheffield was between 2 and 3 times as high as in Lincolnshire (Parts of Lindsey) which is the most rural of the areas distinguished in Table I. Twenty years ago Bristol was said to have between $3 \frac{1}{2}$ and 6 times as much rheumatic heart disease as the surrounding country (Savage, 1931). To-day it seems to have about $1 \frac{1}{2}$ times as much acute rheumatism-with or without heart involvement-as the more rural parts of Lindsey, about the same amount as the County Boroughs of Grimsby and Lincoln, and less than Sheffield. Though the years 1948-50 may not be representative of the usual state of affairs, the apparent variation between the areas is so marked that it has been thought worth while to draw attention to the following points:

(a) The variation exhibits the polarity usually found in infectious diseases, with the highest risk in the most densely populated area and the lowest risk in the most dispersed community.

(b) The cases in Sheffield appear to have been not only more numerous, but also more severe.

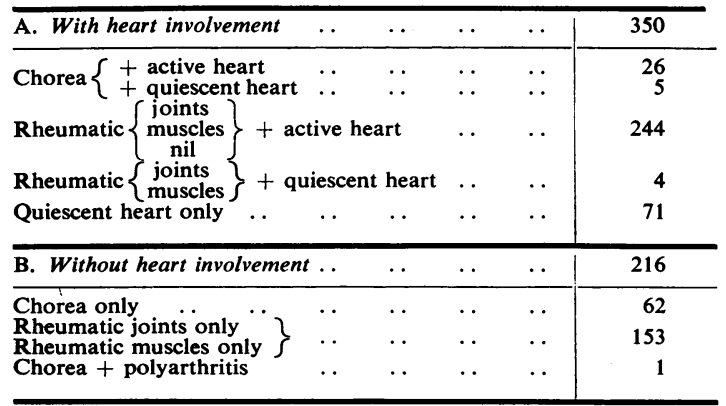

The actual diagnoses are listed above ( 27 cases are omitted because no final diagnosis was available). As a standard of severity we have used the presence or absence of heart disease.

The percentage of cases from the three areas which fell into Group A is shown in Table II.

TABLE II

INCIDENCE (PER CENT.) OF HEART INVOLVEMENT IN THREE AREAS

\begin{tabular}{|c|c|c|c|c|}
\hline \multirow[t]{2}{*}{ Area } & \multicolumn{3}{|c|}{$\begin{array}{l}\text { Interval between Onset and } \\
\text { Examination (months) }\end{array}$} & \multirow{2}{*}{$\begin{array}{l}\text { Total } \\
\text { up to } \\
12 \text { months }\end{array}$} \\
\hline & Under 1 & 1 to 3 & 3 to 12 & \\
\hline Sheffield .. & $\begin{array}{l}57 \cdot 4 \\
(65)\end{array}$ & $\begin{array}{l}66 \cdot 3 \\
(83)\end{array}$ & $\begin{array}{l}69 \cdot 0 \\
(29)\end{array}$ & $\begin{array}{l}63 \cdot 3 \\
(180)\end{array}$ \\
\hline Bristol & $\begin{array}{l}46 \cdot 0 \\
(63)\end{array}$ & $\begin{array}{l}50 \cdot 0 \\
(24)\end{array}$ & & $\begin{array}{l}47 \cdot 3 \\
(93)\end{array}$ \\
\hline $\begin{array}{l}\text { Lincolnshire: } \\
\text { (Grimsby, Lincoln, and } \\
\text { Lindsey) }\end{array}$ & $\begin{array}{l}40 \cdot 7 \\
(27)\end{array}$ & $\begin{array}{l}31 \cdot 0 \\
(29)\end{array}$ & & $\begin{array}{l}31 \cdot 0 \\
(71)\end{array}$ \\
\hline $\begin{array}{l}\text { Significance Test of } \\
\text { Observed Differences }\end{array}$ & $P>\cdot 20$ & $\mathbf{P}<\cdot 01$ & $\mathbf{P}<\cdot 01$ & $\mathbf{P}<\cdot 01$ \\
\hline
\end{tabular}

Numbers at risk are shown in brackets.

Children who had more than one attack, and the few children whose attack preceded the examination by more than one year, are excluded from this Table.

When Table II is compared with Table I it can be seen that variation in the incidence of acute rheumatism is paralleled by a similar variation in the risk of progressing to heart disease. Thus, if Table $I$ is taken to indicate that the risk of acute rheumatism is more than twice as great in Sheffield as in Parts of Lindsey, then the two Tables together must be interpreted as meaning that the risk of rheumatic heart disease is roughly four times as great. The parallelism between Table I and Table II suggests that the factors responsible for determining the risk of an initial attack may also be responsible for determining the risk of heart involvement in persons who have fallen ill. If this interpretation is correct, the figures in Table I may be regarded as evidence of regional variation in the risk of "threshhold" infection, and those in Table II as evidence of a similar variation in the risk of massive or repeated infection.

B. Sex InCIDEnCE.-Boys constituted 50.9 per cent. of the population at risk and only $46 \cdot 4$ per cent. of the cases, but the apparent excess of girls among the cases is not statistically significant. The classification into cases with and cases without heart involvement did not reveal any sex difference, but girls with chorea numbered 64 as against only 28 boys, a difference which is highly significant. The liability of girls to chorea appears to be more than twice as great as that of boys, and substantially 
the whole of the excess of girls is due to the difference in this diagnostic group (Table III).

TABLE III

FREQUENCY OF VARIOUS DIAGNOSES IN THE TWO SEXES

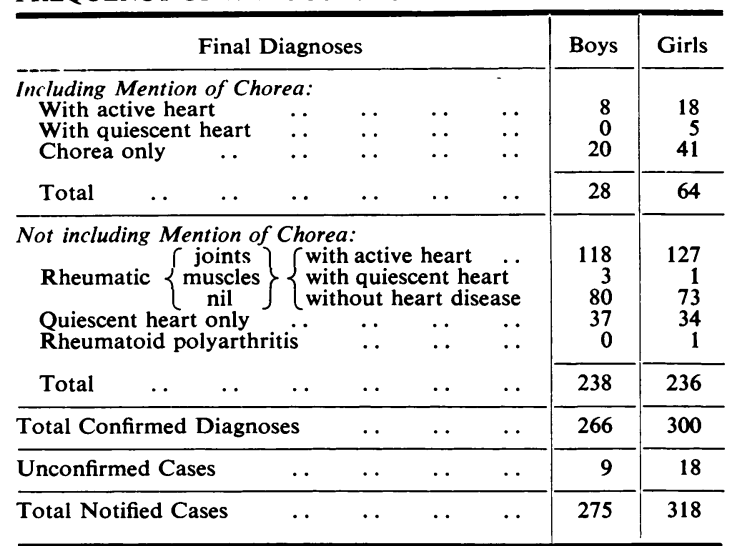

Except in the case of chorea, there appeared to be no sex difference in respect of the age at which children contracted acute rheumatism. But among the choreic cases only six boys ( 21 per cent.) were over the age of 11 , as against thirty girls ( 47 per cent.). Thus, the excess of chorea in girls is largely due to cases occurring at a relatively late age.

C. Seasonal Incidence.-Table IV shows the frequency of first and subsequent attacks of acute rheumatism according to the calendar month of onset. In order to make the monthly totals comparable with one another, cases belonging to the last 3 months of 1947 and to all earlier periods have been excluded. The following cases are also excluded:

(i) those stated to be of "insidious onset";

(ii) those with the diagnosis "quiescent heart only" where no acute illness had been reported;

(iii) attacks intermediate between the first and the last to be reported.

Thus, a child may be included in both columns, but not more than once in either.

TABLE IV

FREQUENCY OF NEW AND OF SECONDARY ATTACKS OF ACUTE RHEUMATISM BY MONTH OF ONSET, 1948-50

\begin{tabular}{|c|c|c|c|c|}
\hline \multicolumn{3}{|c|}{ Month } & New Cases & Secondary Cases \\
\hline $\begin{array}{l}\text { January } \\
\text { February } \\
\text { March .. } \\
\text { April .. } \\
\text { May .. } \\
\text { June . . } \\
\text { July . . } \\
\text { August.. } \\
\text { September } \\
\text { October } \\
\text { November } \\
\text { December }\end{array}$ & $\begin{array}{l}\ldots \\
\because \\
\because \\
\because \\
\because \\
\cdots \\
\cdots\end{array}$ & $\begin{array}{l}\ldots \\
\cdots \\
\cdots \\
\cdots \\
\cdots \\
\ldots \\
\cdots \\
\ldots\end{array}$ & $\begin{array}{r}44 \\
33 \\
25 \\
27 \\
19 \\
30 \\
10 \\
7 \\
16 \\
23 \\
21 \\
25\end{array}$ & $\begin{array}{r}15 \\
10 \\
14 \\
9 \\
5 \\
4 \\
7 \\
6 \\
4 \\
4 \\
5 \\
6\end{array}$ \\
\hline
\end{tabular}

The peak incidence of first attacks is in the winter months of January and February. This is followed by a slow decline to a minimum in August and a rapid rise in the autumn, but the figure for June is the third highest of the twelve and is out of line with the downward trend from winter to summer. The rise between December and January is also unexpectedly large.

The monthly distribution of recurrences also has its peak in the winter, but these are spread more evenly over the year as a whole than are the new cases. The several notification areas showed only minor and insignificant differences in the seasonal pattern.

D. Possible Importance of the School in the SPReAd of Rheumatic Fever.-Bradley (1932) has described an epidemic of rheumatic fever at a boarding school. If school epidemics do occur, compulsory notification should bring them to light, but the records so far available do not contain data suitable for investigation of the possible importance of the school as a factor in incidence.

Two findings, however, are suggestive:

(i) Age at First Onset.-In Table V all the cases are arranged according to age at the first onset of rheumatism, so far as this could be judged from the records.

TABLE V

AGES OF 593 CHILDREN AT FIRST ONSET OF RHEUMATISM

\begin{tabular}{|c|c|c|}
\hline Age (years) & Number of Cases & Cases per Year of Life \\
\hline $\begin{array}{c}0 \text { to } 4 \\
5 \\
6 \text { to } 14 \\
15\end{array}$ & $\begin{array}{r}30 \\
43 \\
508 \\
12\end{array}$ & $\begin{array}{r}6 \\
43 \\
56 \\
12\end{array}$ \\
\hline Total 0 to 15 & 593 & 37 \\
\hline
\end{tabular}

This Table shows that many children had their first experience of rheumatism between their fifth and sixth birthdays; far more, in fact, during this one year of life than during the whole of the first five years. Since this is also the age at which children first go to school, there is evidently a coincidence which deserves further investigation.

(ii) Annual Cycle.-There is a fair correspondence between the school year, September to July, and the annual cycle of new cases. The one month which is a complete holiday for all schools is August, and this is the month with the fewest new cases of rheumatism. The two sharpest increases are in September and in January, and these may correspond to the re-assembly of children for the autumn and spring terms. 
PART II

A. Social AND Environmental Factors.-It is known that rheumatic fever is associated with "the complex of adverse circumstances which accompany poverty" (Ryle, 1946), yet according to the most recent mortality statistics, men in the well-to-do sections of the community are slightly more liable to die of rheumatic fever than their poorer neighbours (Registrar-General, 1931). Miller (1942) also expressed the belief that rheumatic fever is "more rife in the upper and middle classes of the poor than in the very poorest". It was therefore of prime interest to know how the social setting of the cases and controls in Sheffield compared.

The 793 Sheffield children were divided, on the basis of their fathers' occupations, into the five social classes used by the Registrar-General. A comparison of the proportion of cases and of controls which fell into each group revealed an excess of cases at the lower end of the social scale, and since the differences between cases and controls were significant $(P<0.01)$, the degree to which risk of rheumatism varied was estimated by calculating the ratio of actual to expected cases in four social groups. The resulting morbidity ratios are shown in Table VI, Col. A. Cols B and C show the social class mortality ratios given by the Registrar-General (1938).

TABLE VI

ESTIMATES OF FREQUENCY OF ACUTE RHEUMATISM IN VARIOUS SOCIAL CLASSES

\begin{tabular}{c|c|c|c}
\hline & A & B & C \\
\cline { 2 - 4 } $\begin{array}{c}\text { Social } \\
\text { Class }\end{array}$ & $\begin{array}{c}\text { Morbidity Ratio } \\
\text { in Sheffield } \\
\text { Children } \\
1947-50\end{array}$ & $\begin{array}{c}\text { Mortality Ratio: 1930-32 } \\
\text { in Persons aged 20 to 35 }\end{array}$ \\
\cline { 2 - 4 } I and II & 48 & Males & Married Women \\
III & 89 & 104 & 94 \\
IV & 125 & 101 & 102 \\
V & 147 & 104 & 105 \\
\hline All & 100 & 86 & 102 \\
\hline
\end{tabular}

The Sheffield ratios show that rheumatic fever in childhood may be three times as common among the children of unskilled workers as among those of the professional and administrative classes. It is therefore pertinent to discover whether any of the "adverse circumstances" listed in the schedules can be incriminated.

In addition to father's occupation, twenty independent items of information relating to the social, environmental, and financial situation of the children were extracted from the records. These included total weekly income and weekly rent. It was to be expected that the families of cases, being more often of a lower social class, would have considerably less money than the controls, but in fact the differences between cases and controls in respect of family income were trivial. Nor did there prove to be any tendency for the rheumatic families to overspend on rent, either absolutely or relative to income.

No information concerning diet or money spent on food was available, but an index of the opportunity to obtain a good diet was obtained by dividing the amount of money left after payment of rent by the number of people to be fed. The percentages of case and control families which fell into three ranges of this index are shown in Table VII.

\section{TABLE VII}

INCOME AVAILABLE PER HEAD AFTER PAYMENT
OF RENT

\begin{tabular}{l|c|c}
\hline $\begin{array}{l}\text { Amount per Head } \\
\text { Available per Week }\end{array}$ & \multicolumn{2}{|c|}{ Percentage of Families in Range } \\
\cline { 2 - 3 } & Cases & Controls \\
\hline Up to 17s. 11d. & $22 \cdot 9$ & $14 \cdot 9$ \\
18s. to 32s. 11d. & $57 \cdot 0$ & $56 \cdot 8$ \\
33s. and over & $20 \cdot 1$ & $28 \cdot 3$ \\
\hline All Ranges & $100 \cdot 0$ & $100 \cdot 0$ \\
\hline
\end{tabular}

The difference between the distribution of case and control families in Table VII is highly significant: $P\left[\chi_{(2)}^{2} \geqslant 10 \cdot 44\right]<0.01$. Yet it is not of great magnitude, for the average amount of money available per head in the families of cases is about 94 per cent. of that available in the control families. There is, moreover, a fundamental objection to interpreting Table VII as evidence that lack of money has a direct bearing on the risk of acute rheumatism, for, under cover of the standardization for family size, another factor having no essential connexion with poverty has crept in. This factor is family size itself, long recognized as important in all diseases where infection can be involved. It has, in fact, to be allowed that the apparent association between low income per head and risk of rheumatism may be due to a third factor associated with family size rather than to the low income per se.

Before leaving the general topic of financial opportunity, reference should be made to two loosely related items of information on the schedules, namely, the fathers' experience of unemployment and the proportion of mothers working outside the home. The fathers of cases and of controls did not differ in their experience of long-term unemployment, but there was a significant excess of men who had been out of work for short periods among the fathers of rheumatic children. Since such sporadic unemployment is part of the normal lot of unskilled workers and does not involve serious loss of earnings, it is unlikely to be relevant to the incidence of rheumatism among his dependents. 
The mothers were divided into three occupational groups: housewives, and part-time and full-time workers. Employment outside the home (particularly full-time employment) was significantly commoner among the mothers of rheumatic patients than of control children. The economic importance of this finding is not clear, for although a mother's going out to work may be symptomatic of a lack of money, it must, in itself, cause an appreciable addition to the family income.

Fourteen items of information concerning the situation and standard of housing were transcribed from the records and are summarized in Table VIII. The first two lines show that the households of cases had an excess of persons and a deficiency of rooms, and that in both these respects the cases differ significantly from the controls. That is to say, the distribution of rheumatism in Sheffield exhibits a feature which ought to be expected in the case of an infective but not necessarily in the case of a noninfective disease. There was also more statutory overcrowding in the homes of the cases, but this criterion of crowding failed to establish any significant difference between the two groups. In Table VIII the items "occupants" and "rooms" have been cited separately rather than in the form of a density ratio, because it seemed useful to distinguish two elements of density which may be of importance. These are: (i) enforced proximity to other persons in the same household, increasing the risk, if there is already a source of infection in the house, of passing infection from person to person;

(ii) increased risk that infection will be brought into the house.

In large households there is also a greater risk that a member who escapes in the "first generation" of infection will succumb later. Members of large households also run a greater risk of receiving a second dose of infection during some critical period of their own illness or convalescence. This may be of considerable importance in determining whether or not a streptococcal illness develops into rheumatic fever.

With regard to the question of proximity, it must be doubted whether the lack of a sixth or seventh room imposes upon the members of a family any degree of intimacy which they would otherwise avoid. Yet it is only the houses of six or more rooms which are deficient in the sample of cases. On the other hand, the addition of a sixth or seventh member to the family-i.e. a fifth or sixth other member-must be held to constitute an appreciable added risk of having an infective person in the house. It therefore seems reasonable to infer that the association between rheumatism and number of occupants is a direct one; whilst the other element in density-number of rooms-may owe its association with rheumatism to the intermediate factor of economic status. The observation that in the case families there were more mothers who went out to work may also be related to risk of infection, for such mothers are more likely to bring infection home than are housewives.

TABLE VIII

COMPARISON OF HOME CIRCUMSTANCES OF CASES AND CONTROLS

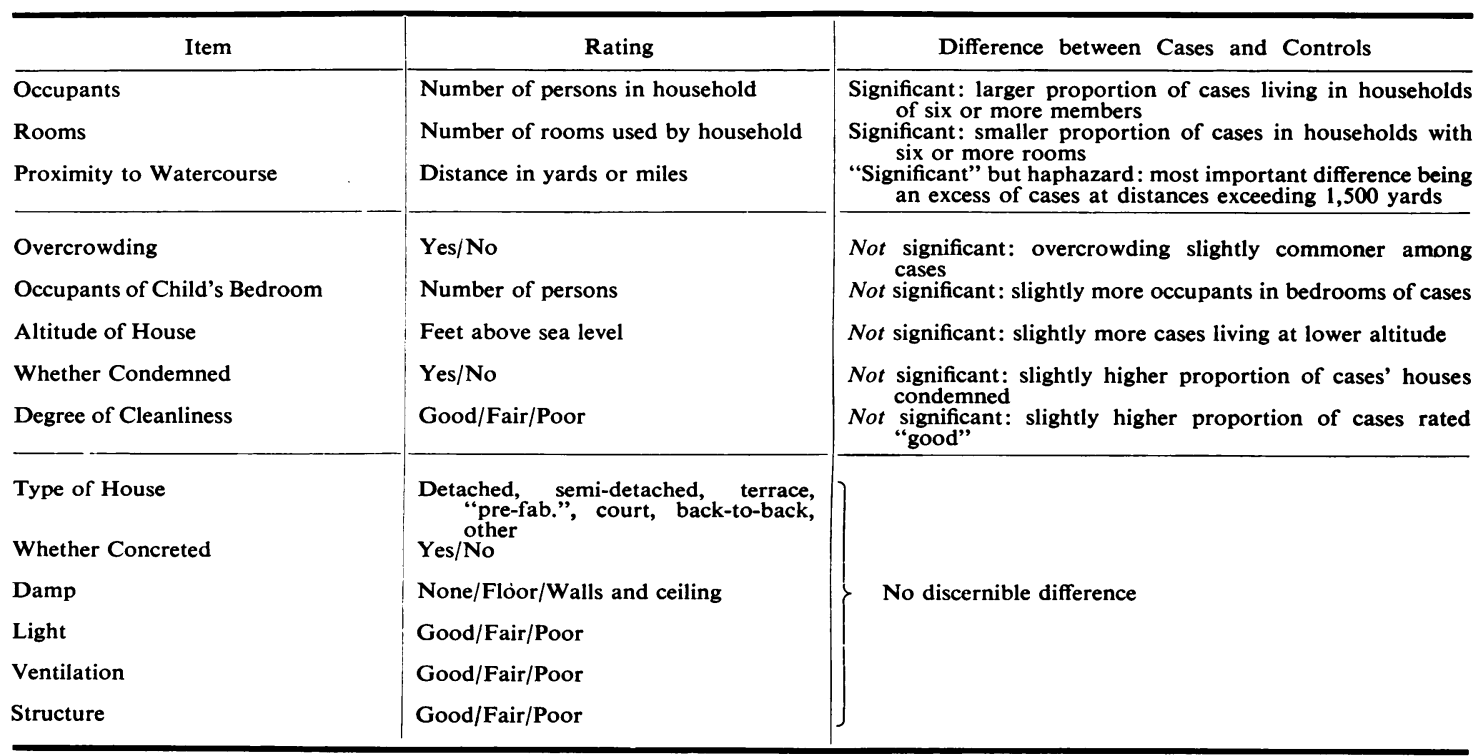


An attempt was made to measure the hypothetical relationship between the risk of acute rheumatism and the number of other members of the household by calculating morbidity ratios of the same kind as those given for the social classes in Table VI. The result is shown in Table IX.

TABLE IX

RELATION BETWEEN HOUSEHOLD SIZE AND RISK OF ACUTE RHEUMATISM

\begin{tabular}{cc|c|r|r|r|r|r}
\hline $\begin{array}{c}\text { Number of Other Per- } \\
\text { sons in Household. }\end{array}$ & 1 or 2 & 3 & 4 & 5 & 6 & 7 or more \\
\hline Morbidity Ratio &. & 87 & 98 & 79 & 108 & 117 & 174 \\
\hline
\end{tabular}

The increase of the morbidity ratio with household size was found to be continuous except for the break at five-member households. No explanation of this discrepancy can be offered, but the main point is clear: household size is associated with risk of rheumatism and may account for much of the variation of this risk between social classes. Some of the residual variation between social classes may also be due to a similar factor, for the risk of neighbourhood contact, like household contact, is likely to be greater in the lower social classes.

Of the eleven other items not discussed above, the distance from the nearest watercourse registered a significant difference between cases and controls. A very slight excess of cases was found in the group living within 50 yards of a watercourse, but the real source of the "significant" difference was the excess of cases at distances exceeding 1,500 yards. This appears to be due to a bias in the completion of the returns: for it is at the greatest distances from water that an estimate of distance is least likely to be attempted, and this item was omitted from more of the control questionnaires (30 per cent.) than of the case questionnaires ( 8 per cent.).

There was a remarkable absence of contrast between cases and controls in the last ten items. It would therefore appear that housing amenities in general, whatever their importance in more chronic forms of rheumatism, have no influence on the genesis of rheumatic fever, and that opportunity for infection is largely responsible for the steep social gradient.

\section{B. Related Illness and Familial Association.-} Infection is clearly not a sufficient cause of the disease, for only a small minority of those infected develop either symptoms of acute rheumatism or the later signs of an unrecognized attack. Hence arose the hypothesis that victims of the disease may be "individuals having an inborn or acquired sensitivity to a common agent-an agent which, in most persons, provokes a local reaction only or produces other types of general response" (Ryle, 1946).

The present survey did not yield data suitable for a rigorous examination of this hypothesis but some of the relevant findings are set out below:
(1) Tonsillectomy.-For reasons connected with the administration of the survey there was under-recording of histories of tonsillitis and other illnesses among the rheumatic patients. There was, however, no known bias in the recording of tonsillectomies performed on children with a history of tonsillitis. This operation had been performed on 19.4 per cent. of the rheumatic cases with tonsillitis as against 57.4 per cent. of the corresponding controls. The difference of 38.0 per cent. exceeds three times its standard error, thus the difference cannot be due to chance; but, though not attributable to chance, this result may be due to some uncontrolled factor in the comparison. For example, such a difference could have arisen if there were many cases where rheumatic fever intervened between a decision to perform tonsillectomy and a suitable occasion for operating, or if selection for tonsillectomy were a function of social class. The first point could not be checked but the original schedules revealed no evidence of social class selection in the control series. As it stands, the evidence suggests that "abnormal" tonsils are a sign of an acquired liability to rheumatic fever which is reduced by about two-thirds when the tonsils are removed (i.e. 42 per cent. of the unoperated but only 14 per cent. of the operated cases of tonsillitis were recorded among the rheumatic fever patients).

(2) Incidence of Rheumatism among Relatives. - It is a regular practice in morbidity studies to collect information on the incidence of the disease among the relatives of patients to find whether it is "high" or "low". This was done in Sheffield and the results demonstrate a tendency for rheumatic manifestations to be more common among the relatives of rheumatic than of non-rheumatic children. It is, however, impossible to say whether the observed differences are too large to be attributed solely to environment.

One way of extending the analysis is to classify relatives according to the degree of blood relationship, for if a familial association depends on hereditary influence the association should be most marked in the nearest relatives. Unfortunately the same expectation applies to the case of a familial association depending on environmental influences. Some evidence has been produced (Griffith and others, 1948) to suggest that the peculiar susceptibility to rheumatic fever of an individual in a "rheumatic family" comes to an end when he is separated from his family. If this is the case, studies based on children and studies based on adults would lead to quite different estimates of the importance of familial association in rheumatism. In short, an analysis by degree of relationship cannot yield unambiguous results unless it is sufficiently refined to distinguish between identical and non-identical twins. Nevertheless, it provides a convenient form of summarizing the data and has accordingly been used in Table X. Here we see that, though the excess of rheumatic persons in the families of rheumatic children is greater for parents than for grandparents, it is lowest of all among siblings. The latter finding could be due to the fact that genetic factors are not operating or that they need prolonged exposure to become manifest, and it 
merely reminds us that a comparison based on childrelatives can be very misleading if no age-standardizing factor is introduced.

TABLE X

FREQUENCY PER CENT. OF RHEUMATIC DISEASES IN THE RELATIVES OF RHEUMATIC FEVER PATIENTS AND OF CONTROL CHILDREN

\begin{tabular}{|c|c|c|c|}
\hline $\begin{array}{l}\text { Relationship } \\
\text { Group }\end{array}$ & $\begin{array}{l}\text { Incidence in } \\
\text { Families of } \\
\text { Patients }\end{array}$ & $\begin{array}{l}\text { Incidence in } \\
\text { Families of } \\
\text { Controls }\end{array}$ & $\begin{array}{c}\text { Estimated Per- } \\
\text { centage excess } \\
\text { of Rheumatic } \\
\text { Persons in } \\
\text { Families of } \\
\text { Patients }\end{array}$ \\
\hline $\begin{array}{l}\text { Siblings } \\
\text { Parents ... } \\
\text { Grandparents } \\
\text { Parents' Siblings }\end{array}$ & $\begin{array}{l}4 \cdot 20 \quad(785) \\
9 \cdot 40 \quad(638) \\
4 \cdot 15(1,276) \\
2 \cdot 96(2,534)\end{array}$ & $\begin{array}{l}3 \cdot 09(1,005) \\
5 \cdot 57 \quad(934) \\
3 \cdot 59(1,868) \\
2 \cdot 46(3,823)\end{array}$ & $\begin{array}{l}14 \\
69 \\
16 \\
20\end{array}$ \\
\hline All Relatives & $4 \cdot 22(5,233)$ & $3 \cdot 20(7,630)$ & 32 \\
\hline
\end{tabular}

Numbers at risk are shown in brackets.

The following histories are excluded from the table: heart disease of uncertain origin, rheumatic arthritis, ill-defined rheumatics.

A second method of analysis is to distinguish between different forms of rheumatism in the propositi and their relatives. For example, Campbell (1934) claimed to have found that

family history was important as regards the particular type of rheumatic disease; where there was chorea in one generation it was more likely to occur again in another generation.

In this survey, children with chorea reported a family history of rheumatism no more frequently than other rheumatic children. But among the choreic children who did have a positive family history, the percentage including chorea was 25.5 per cent. as against 10.9 per cent. for the non-choreic cases with a positive family history, and the difference of $14 \cdot 6$ per cent. exceeds twice its standard error. The present material thus reproduces Campbell's finding. (Cases from all areas were included in this comparison to make the numbers large enough for a statistical test.)

A division of relatives into those on the paternal and maternal sides of the family was also made, but this yielded no evidence to suggest that a rheumatic diathesis had passed more frequently through either the female or the male line.

(3) Pigmentation.-Following the precedent of the M.R.C. Report of 1927, an attempt was made in Sheffield to observe the hair and eye colour of cases and controls. It became necessary in the course of analysis to reduce the colour descriptions to: "blue" and "other" in the case of eyes; and "fair", "blonde or corn", and "other" in the case of hair. The distribution of eye colours was, in the cases $44 \cdot 1$ per cent. blue and 55.9 per cent. other colours, and in the controls 61.5 per cent. blue and 38.5 per cent. other colours; the difference is too large to be attributed to chance $(P<0.01)$ and accords with the finding of the earlier survey. The figures obtained in Sheffield imply that the risk of acute rheumatism is twice as great for children with eyes of "other" colours as for blue-eyed children $\left(\frac{55 \cdot 9}{38 \cdot 5} \div \frac{44 \cdot 1}{61 \cdot 5}=2 \cdot 02\right)$. There was also a slight deficiency of fair-haired children in the rheumatic series but this was not statistically significant.

(4) Relationship between Severity of Rheumatism in Parent and in Child.-It was of some interest to know whether, among rheumatic children with a positive parental history of rheumatism, the severity of the disease in the parents has any bearing upon the severity of the disease in the child. As a measure of severity we have again used the criterion of heart involvement but this was complicated by uncertainty as to the nature of "heart disease" in some deceased parents. Whether or not such disease was assumed to have been rheumatic in origin there appeared to be a slight association between heart involvement in rheumatic parent and rheumatic child. The associations were of bordertine significance $(P=0.07$ to 0.05$)$. This finding accords equally well with the hypotheses that familial association in rheumatism is due to genetic, and that it is due to environmental factors.

\section{SUMMARY}

(1) Acute rheumatism is commoner in Sheffield than in three other notification areas, and is least common in the more rural parts of Lindsey. The variation in the incidence of rheumatic heart disease is even more extreme.

(2) Children of unskilled workers suffer from rheumatism far more commonly than do children of professional and skilled workers.

(3) There is no evidence that rheumatism is associated either with bad housing conditions or poverty, per se.

(4) Risk of rheumatism appears to be greater where opportunities for infection are high: in the town as against the country, the large family as against the small, in children of school age as against children of pre-school age. Differences in the risk of infection may be responsible for the social gradient of rheumatism in childhood, and the association between income per head and incidence of acute rheumatism.

(5) There is no evidence in this survey to justify the belief that some families are more prone than others to develop rheumatism. On the other hand blue-eyed children appear to have only one half the liability to acute rheumatism that is suffered by other children, and this is evidence of some genetic factor operating.

(6) There is a well-marked seasonal fluctuation in the incidence of acute rheumatism which has its peak in January. The seasonal pattern may owe something to the periodic re-assembly of children for school terms.

(7) Girls suffer from chorea more frequently than boys, and the excess of chorea among girls increases after the age of 11. Otherwise there is no difference between the sexes. 
(8) There is some evidence that children with tonsillitis run less risk of a subsequent attack of rheumatic fever if their tonsils have been removed.

We wish to express our gratitude to the Medical Officers of Health in each notification area for their interest and advice, and for their having placed all their records at our disposal. The expenses of the study were covered by a grant from the Royal College of Physicians.

\section{REFERENCES}

Bradley, W. H. (1932). Quart. J. Med., 25 (n.s. 1), 79

Campbell, M. (1934). In "The Chances of Morbid Inheritance", ed. C. P. Blacker, pp. 246-279. Lewis, London.

Griffith, G. C., Moore, F. J., McGinn, S., and Cosby, R. S. (1948). Amer. Heart J., 35, 444.

Medical Research Council (1927). Spec. Rep. Ser., No. 114.

H.M.S.O., London.
Miller, R. (1942). Lancet, 2, 563.

Miller, R. (1942). Lancet, 2, 563. Wales, 1931". Part IIA: Occupational Mortality, p. 50. H.M.S.O., London.

(1949). "Estimates of the Sex and Age Distribution of the Civilian Population, 1947". H.M.S.O., London.

Ryle, J. A. (1946). J. roy. San. Inst., Trans., 66, 277. 